\title{
Sleep and survival among women with breast cancer: 30 years of follow-up within the Nurses' Health Study
}

Claudia Trudel-Fitzgerald ${ }^{1}$, Eric S Zhou ${ }^{2,3}$, Elizabeth M Poole ${ }^{4}$, Xuehong Zhang ${ }^{4,5}$, Karin B Michels ${ }^{6}$, A Heather Eliassen ${ }^{4,5}$, Wendy Y Chen $2,3,4$, Michelle D Holmes ${ }^{4,5}$, Shelley S Tworoger ${ }^{4,5}$ and Eva S Schernhammer ${ }^{4,5,7}$

${ }^{1}$ Department of Social and Behavioral Sciences, Harvard T.H. Chan School of Public Health, 677 Huntington Avenue, Boston, MA 02115, USA; ${ }^{2}$ Department of Medicine, Harvard Medical School, 25 Shattuck Street, Boston, MA 02115, USA; ${ }^{3}$ Department of Medical Oncology, Dana-Farber Cancer Institute, 450 Brookline Avenue, Boston, MA 02215, USA; ${ }^{4}$ Department of Medicine, Channing Division of Network Medicine, Brigham and Women's Hospital, 181 Longwood Avenue, Boston, MA 02115, USA; ${ }^{5}$ Department of Epidemiology, Harvard T.H. Chan School of Public Health, 677 Huntington Avenue, Boston, MA 02115, USA; ${ }^{6}$ Department of Epidemiology, UCLA Fielding School of Public Health, 650 Charles E Young Dr S, Los Angeles, CA 90095, USA and ${ }^{7}$ Department of Epidemiology, Medical University of Vienna, Kinderspitalgasse 15, Vienna 1090, Austria

Correction to: British Journal of Cancer (2017) 116, 1239-1246. doi:10.1038/bjc.2017.85; published online 30 March 2017

Since the publication of this manuscript, the authors realised affiliation 7 was listed incorrectly. The correct address is now listed above.
This work is published under the standard license to publish agreement. After 12 months the work will become freely available and the license terms will switch to a Creative Commons AttributionNonCommercial-Share Alike 4.0 Unported License. 